\title{
Codeforces as an Educational Platform for Learning Programming in Digitalization
}

\author{
Mike MIRZAYANOV, Oksana PAVLOVA, Pavel MAVRIN, \\ Roman MELNIKOV, Andrew PLOTNIKOV, Vladimir. PARFENOV, \\ Andrew STANKEVICH
}

ITMO University, Saint-Petersburg, Russia

e-mail:mrmirzaianov@itmo.ru,onpavlova@itmo.ru,mavrin@itmo.ru,rvembox@gmail.com, shemplo@outlook.com,parfenov@mail.ifmo.ru,stankev@gmail.com

\begin{abstract}
Digitalization imposes ways of development and influences the process of Codeforces development. Codeforces' infrastructure provides a solid open ecosystem for building a programming learning process. Functionality covers the entire process, from the Polygon system for devising problems to mashup contests and private groups on Codeforces. A beta test of the educational subsystem with a pilot educational course was launched. The paper describes all the aspects and relationships of the ecosystem, typical flows of use, examples of successful integration into educational processes in the age of digitalization.
\end{abstract}

Keywords: educational platforms, competitive programming platforms, sports programming, elearning, Olympiads and hackathons in Informatics, education digitalization.

\section{Introduction}

Digitalization becomes possible when there is the development of digital infrastructures and communication standards, information security, the expansion of online learning (e-learning), access and ability to use online-services and a lot of qualified IT-specialists who can create and develop information technologies, on-line services and others. Nowadays there is a shortage of IT-specialists all over the world. Their need in Russian IT- industry is 62400 people and their need in other industries of Russia is 82600 people. Enrollment in higher education institutions for IT majors in 2024 in Russian universities should be 120 thousand applicants. To ensure this number, it is necessary to train, motivate and attract more schoolchildren interested in IT and reform educational system, making it possible to teach a vast number of students. 


\section{Codeforces as a Platform for Programming Contests}

In the world there are several mostly used contest's platforms such as American Topcoder, Indian CodeChef, Japanese AtCoder, European CSAcademy and Russian Codeforces. Codeforces is an international platform that hosts the largest regular Internet programming and Informatics competitions (Olympiads and hackathons), posts articles in IT-field, organizes programming trainings, discusses competitions \& training tasks, and various news from IT-community. This is the largest training resource in the world, which provides an open infrastructure for preparing and conducting programming competitions, as well as automation of programming training courses.

Codeforces provides a wide range of services for those who are interested in algorithmic tasks and programming competitions. The main goal of Codeforces as a platform for competitions is to provide an opportunity to unite all those interested in programming contests, providing a wide list of services for this area of interest. The platform supports Russian and English languages and most of the materials are presented in two languages.

For many years Codeforces has provided three services:

- Social network (with various classic social network services and some specialized solutions).

- Subsystem of the competitions.

- Subsystem of hosting trainings.

Since December 2019 Codeforces has become the educational platform as well.

\subsection{Testlib}

Testlib library for $\mathrm{C}++$ has been developed since 2005 as a replacement for an outdated similar library for the Pascal language. Currently, Testlib for $\mathrm{C}++$ includes significantly more functionality compared to Testlib for Pascal. The new library has become the de facto standard for developing $\mathrm{C}++$ tasks and programming tasks.

The library is widely used in the jury's work of various Olympiads and competitions:

- All the stages of All-Russian Olympiad of schoolchildren in Informatics (computer science).

- All the stages of All-Russian Team Olympiad of schoolchildren in programming.

- Repeatedly used in the development of tasks for the International Olympiad in Informatics (IOI).

- Dozens of regional competitions of the world student programming championship (ICPC).

- Many University competitions in Russia and abroad.

- Most stages of training camps (schools) in Russia and abroad.

- All rounds of open Codeforces competitions. 


\subsection{Polygon System}

Polygon is a system for developing problems (task). Work on the Polygon system was started in 2008. Since March 2009, the system has been available online for everyone. Polygon simplifies and unifies the work of authors of programming problems and jury members of computer science and programming Olympiads. This is the only system of its kind with advanced functionality and accessibility to a wide range of problem authors.

Key features of Polygon that are an advantage of using it over other ways of developing problems are below:

- The Polygon system protects against errors.

- A lot of automation and self-checking tools are built into the Polygon:

- The system protects against typos in tests from the condition and from the fact that they are not updated after changing the tests, since tests from the condition are inserted automatically, and responses to them are generated by the system by the author's decision.

- All source texts in the problem archive (solutions, generators, checker, validator, etc.) will be compiled and correspond to the current versions.

o The system displays a warning that the first test is not a test from the condition.

- If the system checks that the non-deterministic generator (which is initialized from the current system time) is not being used, it will run the generator twice at intervals of a second and make sure that the tests match.

- The Polygon system implements dozens of similar checks that effectively prevents errors or ignoring good practices in problem development.

- Archives (packages) of Polygon tasks are uniform and machine-readable.

- Polygon provides long-term storage and availability of issues and competitions.

- Polygon reduces the threshold for entering the task preparation process.

- The system helps you manage access.

- Polygon has built-in issue-tracking.

- Polygon provides easy integration with automated testing systems.

- There are no special software requirements for the task developer.

- Polygon is attentive to security issues and data leaks.

- Polygon has built-in tools for classifying, indexing, and searching for issues.

According to Google Analytics, Codeforces is ahead of its competitors in terms of the number of competitions per month, the number of participants. Codeforces has an open registration system. The number of registered users is constantly growing. At the end of 2019, the main metrics according to web analytics system "Google Analytics" were:

- 472158 users.

- 29138871 page views.

- Average session duration: 15 minutes.

Judging by the metrics Codeforces has a huge potential for creating on its basis an educational subsystem for participants of Olympiad programming. 


\section{Codeforces as a Platform for Education}

\subsection{The Concept of Educational Platforms}

The debate rages in impact and effectiveness of e-learning, its benefits and drawbacks, motivations, performance and barriers (Alias et al., 2012), (Zakariah, et al., 2012), (Khan et al., 2019), (Shapiro et al., 2017), (Al-Rahm et al., 2015) (Shoufan, 2019), (Shin et al., 2019), (Magalhães et al., 2020). This topic is becoming very actual in the time of Covid-19 pandemic. The significance of e-learning possibilities has changed and grown.

\subsection{Existing Educational Solutions}

Nowadays many online learning resources exist all over the world - Coursera, edX, YouTube, Udemy, Khan Academy. But only some of them have courses on competitive programming. The main metrics are presented in Table 1.

However existing educational platforms such as Coursera, Stepik, Universarium, EdX and others do not offer programming competitions. Moreover, the courses presented by these platforms do not meet the requirements of courses on Olympiad programming.

To conduct a comparative analysis of existing courses, the most closely related courses were selected, which are also considered the most popular in IT-community:

- The course "Sports programming" is available on the Stepik and Coursera platforms. It is the closest course in the subject

https://ru.coursera.org/learn/sportivnoe-programmirovanie

- The course "How to Win Coding Competition: Secrets of Champions" on the Edx platform. It is a similar course in English https : / www . edx .org/course/ how-to-win-coding-competitions-secrets-of-champions-4

- The course "Algorithms and data structures" on the Stepik platform https:// stepik.org/course/63

The comparison is shown below in Table 2 .

Table 1

The main metrics of similar courses.

\begin{tabular}{llll}
\hline Platform & Stepik \& Coursera & Edx & Stepik \\
\hline Name of the course & Sports programming & $\begin{array}{l}\text { How to Win Coding Competitions: } \\
\text { Secrets of Champions }\end{array}$ & $\begin{array}{l}\text { Algorithms and data } \\
\text { structures }\end{array}$ \\
Metrics & & 78015 & 16286 \\
registed & 2430 & 191 & 542 \\
Issued certificates & 129 & & \\
\hline
\end{tabular}


Table 2

Comparison of algorithms and data structure courses

\begin{tabular}{llll}
\hline Platform & $\begin{array}{l}\text { Stepik \& } \\
\text { Coursera }\end{array}$ & Edx & Stepik \\
\hline Name of the course & $\begin{array}{l}\text { "Sports } \\
\text { programming" }\end{array}$ & $\begin{array}{l}\text { "How to Win Coding Competitions: "Algorithms and } \\
\text { Secrets of Champions" }\end{array}$ \\
\hline
\end{tabular}

Course contents (main topics that should be covered in competitive programming)

\section{Bactracking}

Stack, queue

Segment tree

Union-Find

Greedy algorithms

Dynamic programming

String algorithms

DFS, Topological sorting

Shortest paths

Binary search

Binary climbing

Graph games

Combinatorics

Bitmasks

Numbers theory algorithms

Network flows

Matchings

\section{$+$}

$+$

$+$

$+$

$+$

$+$

$+$

$+\quad+$

$+\quad+$

(1)

Number and level of practical tasks in the form of problems

Number of practical tasks in not presented the form of problems on programming for each topic

Level of offered task in the not presented form of problems on programming

Possibility to choose separate lectures, topics and problems

Access to the solutions of participants

Possibility to write comments Availability of social networks for discussions

Possibility to get personal recommendations from teacher or coaches on the average 10 problems for each on the average topic 5 problems for each topic

mainly training problems + one-two almost all the probproblems similar to Olympiad prob- lems are training lems ones

not presented not presented

not presented

not presented not presented not presented

not presented not presented not presented

not presented not presented not presented

not presented not presented not presented

Comparative analysis showed that the existing courses have a number of disadvantages, including:

- The material is presented in a difficult language, that is the material is intended for a more adult audience. 
- Theoretical orientation (not practical).

- Basic (not advanced) level.

- They cover only a small part of the topics required for successful participation in computer science and programming Olympiads.

The authors of the paper claim that similar courses have three significant drawbacks:

- They are isolated from the competitors' community on third-party educational platforms.

- The presence of a community on Codeforces not only provides a database of participants interested in the course, but also creates a social environment for participant's communication, discussion, mutual assistance, etc.

- They use an insufficiently developed testing automation infrastructure. Support for programming tasks even of the largest educational platforms lags far behind the support for similar tasks on Codeforces.

\subsection{Codeforces - a Platform for Education}

Codeforces is well-known all over the world as a platform for contests, but lately Codeforces became the educational platform as well. The edu system has been running for three months. During this time three lessons were introduced to the users. Each lesson consists of 4-5 steps, each step includes:

- Lecture video of the algorithm (whiteboard or presentation).

- Lecture text notes.

- Coding video, explaining how to implement the algorithm.

- Programming tasks for practice.

These elements can be used in any order and independently as well as the lessons themselves. Everything is at the discretion of the learner - the pace, the order, the speed of the video, the number of problems.

The lessons were studied by approximately 3000 users. Three-month experience shows that e-learning is of great demand and the combination of platform for contests and education is very popular with IT-community. Especially it is popular with undergraduate students and schoolchildren - future IT-specialists. One can participate in codecups, learn and have talks with like-minded people at one place which is comfortable and convenient. 47 users left the feedback about edu system on Codeforces and it turned out to be highly positive. The feedback is presented in Table 3 .

The feedback shows that users themselves like the idea of the educational project on the contest platform and edu project is in great demand among teens who are interested in hi-tech, Informatics and programming. 
Table 3

How students express their praise or critics in relation to a new format

\begin{tabular}{l} 
Aspect $\quad$ Users' feedback \\
\hline Praise from users \\
\hline Cool! Continue to do such courses! Helps a lot. \\
COOL!!! Good Job and Good Luck. Thanks for such an opportunity!!! \\
This can help us to improve our programming skills and our knowledge. Good Job! \\
Yeah that is right ! thanks a lot. \\
Super! Thank you for such excellent courses! This helps not only beginners, but also advanced \\
users. Excellent lectures, theory and practice! By the way, you are very cool to explain!) P.S. I \\
would Really like more of these courses) \\
Keep doing this great job! Thanks a lot! \\
Interesting form of presentation. This option must clearly exist! Thank you for the quality \\
courses! \\
Good new system. It would be great to study more different strong algorithms. \\
I have always dreamed of such a course, thank you very much! \\
Just what was missing!!! Well done!! \\
It is very cool in codeforces not only to solve problems but also to learn. It has become the \\
main advantage of the platform and soon everything will be better \\
Thank you so. Please don't stop. Your lectures are very useful and I really want to watch that \\
more.
\end{tabular}

\section{Critics and Recommendations from users}

It would have been good to see solutions of other users if you solved the problem yourself. Thanks! The only thing I would like is open tests for detecting errors.

I suggest increasing the scale of the lecturer by 2-2.5 times.

It would be cool if you added moving (rewinding) through the video with the help of the keyboard (the same arrows)

Can you make so that the video continues where it is left off after you switch to practice?

Good lectures. The problems are interesting. It may be worth making the player's buttons bigger so that you could watch it via smartphones.

A good course, and most importantly in demand. It is definitely worth developing further. I didn't find any special disadvantages for myself, so continue in the same way!

When will be the continuation?

\section{Conclusion}

The development of a new format opens up a number of opportunities and has a huge practical significance. The combination of platform for contests and education give possibility to train and study at one place. Distant format provides teens with the possibility to learn for those who live in remote regions where there are no teachers and possibility for children and teenagers with a disability. Learning and contest participation is highly beneficial pastime especially during epidemics. Such approach can be used as a supplementary means in teaching because such platforms attract young people to competitions and in-depth programming studies, they facilitate to cover a wide range of topics and enlarge the number of learners, helping to nurture and form intellectual capital of any country. 


\section{References}

Alias, N., Zakariah, Z., Ismail, N. Z., \& Aziz, M. N. A. (2012). E-Learning successful elements for higher learning institution in Malaysia. Procedia-Social and Behavioral Sciences, 67, 484-489. DOI: 10.1016/j. sbspro.2012.11.353.

Al-Rahmi, W. M., Othman, M. S., \& Yusuf, L. M. (2015). The effectiveness of using e-learning in Malaysian higher education: A case study Universiti Teknologi Malaysia. Mediterranean Journal of Social Sciences, 6(5), 625-625. DOI: 10.5901/mjss.2015.v6n5s2p625.

Khan, M. L. H., \& Setiawan, A. (2019). The impact of E-learning on higher education perception, skills, critical thinking and satisfaction. Journal of Physics: Conference Series, 1375(1), 012084. DOI:10.1088/17426596/1375/1/012084.

Magalhães, P., Ferreira, D., Cunha, J., \& Rosário, P. (2020). Online vs traditional homework: A systematic review on the benefits to students' performance. Computers \& Education, 103869. DOI: 10.1016/j. compedu.2020.103869.

Shapiro, H. B., Lee, C. H., Roth, N. E. W., Li, K., Çetinkaya-Rundel, M., \& Canelas, D. A. (2017). Understanding the massive open online course (MOOC) student experience: An examination of attitudes, motivations, and barriers. Computers \& Education, 110, 35-50. DOI: 10.1016/j.compedu.2017.03.003.

Shin, J., Gruenberg, K., \& Brock, T. (2019). A novel online platform promotes asynchronous class preparation and thought transparency. Currents in Pharmacy Teaching and Learning, 11(10), 1069-1076. DOI: 10.1016/j.cptl.2019.06.015.

Shoufan, A. (2019). What motivates university students to like or dislike an educational online video? A sentimental framework. Computers \& Education, 134, 132-144. DOI:10.1016/j.compedu.2019.02.008.

Zakariah, Z., Alias, N., Aziz, M. N., \& Ismail, N. Z. (2012). E-Learning awareness in a higher learning institution in Malaysia. Procedia-Social and Behavioral Sciences, 67, 621-625. DOI: 10.1016/j.sbspro.2012.11.368.

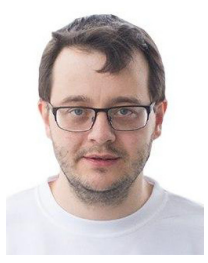

M.Mirzayanov is a founder and CEO of Codeforces and a teacher of the Faculty of Information Technologies and Programming (FITP) of ITMO University. In 2009 he coached ICPC World Champions team of Saratov University and in 2008 he coached ICPC NEERC Champions team of Saratov University. Since 2009 he has been the head of the jury of ICPC Southern Subregional NEERC. From 2008 to 2012 he was a jury member of final stage of Russian Olympiad in Informatics. In 2009 he founded Polygon - service to prepare programming problems and contests. In 2010 he founded Codeforces programming contests community and regular Internet competitions. He was a chairman of the jury and the organizing committee of numerous championships held on Codeforces. 

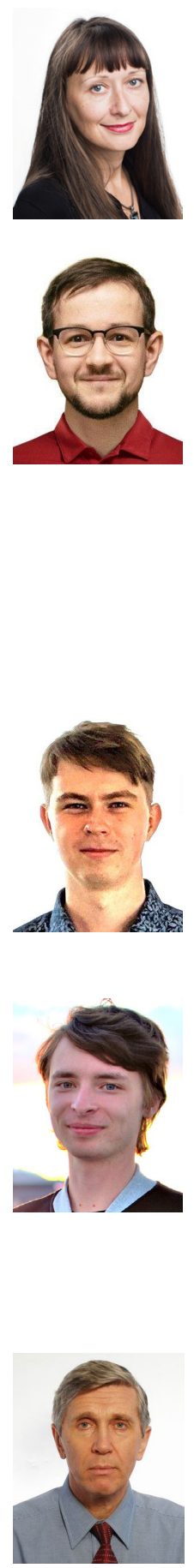

O. Pavlova is an assistant dean for university-business cooperation \& students' well-being of the Faculty of Information Technologies and Programming (FITP) of ITMO University. Her main research interest and main professional focus is ways \& mechanisms of higher education development, the creation of university and business ecosystem and ways of their cooperation.

P. Mavrin is a teacher of FITP of ITMO University. From 2014 to 2017, he was a member of the International Scientific Committee of the International Olympiad in Informatics (IOI). In 2016 he was a chairman of the Host Scientific Committee of the IOI. In 2018 he was a chairman of the Scientific Committee of the European Junior Olympiad in Informatics (eJOI). Since 2019 he has been a chairman of the Scientific Committee for the "British Programming Challenge" in London. He was given the President Award for success in the IOI (2003), St. Petersburg Youth Award in the field of information technology (2005), Saint Petersburg Government Award to teachers-mentors for preparation of winners and prize-winners of all-Russian Olympiads $(2009,2015,2016,2017,2018)$.

R.Melnikov is a master student with major in Applied Maths and Informatics. He graduated with a bachelor's degree of ITMO University in 2019. Currently he is studying at FITP, working as a software engineer in Serokell OU, doing research for optimization problems in nanophotonics along with Physics department at ITMO University, assisting with Computer architecture and Functional programming courses at ITMO University.

A.Plotnikov is a master student with major in Applied Maths and Informatics. He graduated with a bachelor's degree of ITMO University in 2019. He leads the hobby group "Paradigms of programming" for 1st year undergraduate students; works as a senior programmer in the company "Omnics, Inc.". From 2015 to the present, he has been participating as a volunteer and coordinator of volunteers at the regional final "NERC" of the sports programming competition. Since 2015 he has been a teacher at the summer mathematical school "Spectrum", Kazan.

V. Parfenov is a professor and dean of the Faculty of Information Technologies and Programming of ITMO University, a member of international organizing committee of ICPC, the director of ICPC Northern Eurasia Finals. He is one of the main organizers and creators of national and international competitions in computer science and programming for students in Russia. He has contributed a lot to the formation of educational system of search and training gifted students in mathematics, physics, computer science and programming. 


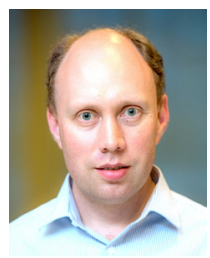

A. Stankevich is an associate professor at ITMO University. He is the Chief Judge at Russian Olympiad in Informatics (since 2019), St Petersburg Olympiad in Informatics (since 1999), Russian High School Team Olympiad in Informatics (since 2000), Individual Olympiad in Informatics (since 2009). He has been the head of Russian Central Methodical Committee in Informatics (since 2019). Judge at NERC (since 2003), Russian Olympiad in Informatics (2000-2018). Russian Delegation at IOI leader $(2016,2018,2019)$. Projects: PCMS Judging System (pcms.itmo.ru), School Olympiads in Russia (nerc.itmo. ru/school), Summer Informatics School (lksh.ru). Awards: President Award in Education (2003), St Petersburg Youth Award in IT (2009), ICPC Silver and Gold Medals (2000, 2001), Seven times ICPC World Champions as Coach (2004, 2008, 2009, 2012, 2013, 2015, 2017), ACM ICPC Founder's Award (2008), ACM ICPC Senior Coach Award (2018), De Blasi Award (2013). 